\title{
Can a gentamicin-specific chart reduce neonatal medication errors?
}

\author{
Christopher Flannigan' \\ Sandra Kilpatrick ${ }^{2}$ \\ Jilly Redpath ${ }^{2}$ \\ Martina Hogan ${ }^{2}$
}

'Royal Jubilee Maternity Hospital, Regional Neonatal Unit, Belfast, Northern Ireland; ${ }^{2}$ Craigavon Area Hospital, Neonatal Unit, Portadown, Northern Ireland
Correspondence: Christopher Flannigan Royal Jubilee Maternity Hospital, Regional Neonatal Unit, Grosvenor Road, Belfast, BTI 2 6BA, Northern Ireland Tel +44289063224l Email cflannigan@doctors.org.uk
This article was published in the following Dove Press journal:

Clinical Audit

22 April 2010

Number of times this article has been viewed

Objective: To evaluate whether the introduction of a gentamicin prescription, administration and monitoring chart reduces the number of medication errors.

Setting: The neonatal department of a district general hospital in Northern Ireland.

Design: A retrospective audit looking at all the reported clinical incident forms involving gentamicin over a 7-year period between 2002 and 2008.

Results: Since the introduction of the new chart in 2005 there was a $16 \%(0.75)$ reduction in the average annual number of medication errors involving gentamicin from 4.75 to 4.00 . There were no further incidents recorded where the wrong dose of gentamicin was given or where a dose was given despite a high serum concentration. There has also been a $67 \%$ reduction in incidents where a gentamicin level was not monitored as required.

Conclusion: There has been some improvement in the number of gentamicin-based clinical incidents with the introduction of a gentamicin-specific chart, however errors are still occurring. Recommendations include the introduction of regular training on appropriate gentamicin prescribing for new staff and a mandatory yearly update for permanent staff. There is a plan to re-audit this yearly, with consideration of electronic prescribing.

Keywords: gentamicin, audit, medication errors, neonatal

\section{Introduction}

Incident reporting and audit are both well-established tools in assessing clinical effectiveness. Since the onset of incident reporting, medication errors have been noted to be one of the most common reasons for reporting a clinical incident ${ }^{1}$ and antibiotics have been shown to be one of the most common drugs associated with medication error in children. ${ }^{2}$ This trend was also noted in the neonatology department in Craigavon Area Hospital, a busy district general hospital with 3900 deliveries per year. Despite medication errors being one of the most commonly reported incidents, gentamicin made up a much higher proportion of the clinical incidents than one would expect in light of total number of doses of all medicines administered. A recent report by the National Patient Safety Agency identified similar problems with gentamicin in children. ${ }^{3}$ There are a number of reasons why this may be the case.

Firstly, gentamicin is recognized as a high risk medicine with a narrow therapeutic margin between efficacy and toxicity. ${ }^{4}$ Its prescription is complicated by the fact that the dosing interval varies depending on the gestational age of the baby. It also requires monitoring of the serum level at specific times and adjustments to dosage made depending on the level. The risk of error is further contributed to

submit your manuscript | www.dovepress.con 
by the fact that it is often prescribed and administered by junior doctors.

As well as representing a significant percentage of clinical incidents, gentamicin has the potential to result in more serious consequences than other antibiotics with its side effects including vestibular and auditory damage, nephrotoxicity, and antibiotic associated colitis. ${ }^{4}$

\section{Objective}

The objective of this study was to determine if the introduction of a new gentamicin chart has reduced the number of clinical incidents involving gentamicin and whether any further action is required.

\section{Standard}

There should be no clinical incidents involving gentamicin.

\section{Method}

A multiprofessional pediatric governance group has been reviewing clinical incidents for the past nine years. Despite provision of training and education on gentamicin prescribing, pharmacists noted that medication incidents involving gentamicin continued to be reported and proposed use of a separate prescription, administration, and monitoring chart for gentamicin in neonates in 2005. The chart was designed to address the medication incidents that had been reported and support adherence to prescribing, administration, and monitoring protocols. The chart was piloted prior to introduction and training and education was provided to staff. A further modification was made to the chart in 2007 requiring the day of the week to be specified to minimize risk of confusion over the date of administration, a particular problem where 36-or 48-hour dosing is required.

The new gentamicin chart (Figure 1) has a number of perceived advantages over prescribing gentamicin on the standard prescription chart. It includes written advice for the prescriber regarding how to work out the dose of gentamicin and the frequency of administration depending on gestational age. Each dose is prescribed individually and numbered to help reduce the recurrence of previous incidents where gentamicin was prescribed or administered at the wrong time, a particular risk where administration occurs less than once a day. A visual prompt is included to remind that a trough sample should be taken before the third dose and an area is

\section{PRESCRIPTION FOR GENTAMICIN (IV) FOR NEONATES}

Dose regime for newborn infant $<7$ days postnatal age:

\begin{tabular}{|l|l|l|}
\hline $\begin{array}{l}\text { Age } \\
\text { (Gestation) }\end{array}$ & Dose & Frequency \\
\hline$>30$ weeks & $4 \mathrm{mg} / \mathrm{kg}$ & 24 hourly \\
\hline $\begin{array}{l}<30 \text { weeks } \\
\text { or }<1 \mathrm{~kg}\end{array}$ & $4 \mathrm{mg} / \mathrm{kg}$ & 36 hourly \\
\hline
\end{tabular}

Gentamicin must be refrenced on the main Kardex by prescribing GENTAMICIN 'as per chart' in the injectable section.

infants $>7$ days postnatal age, see BNFC
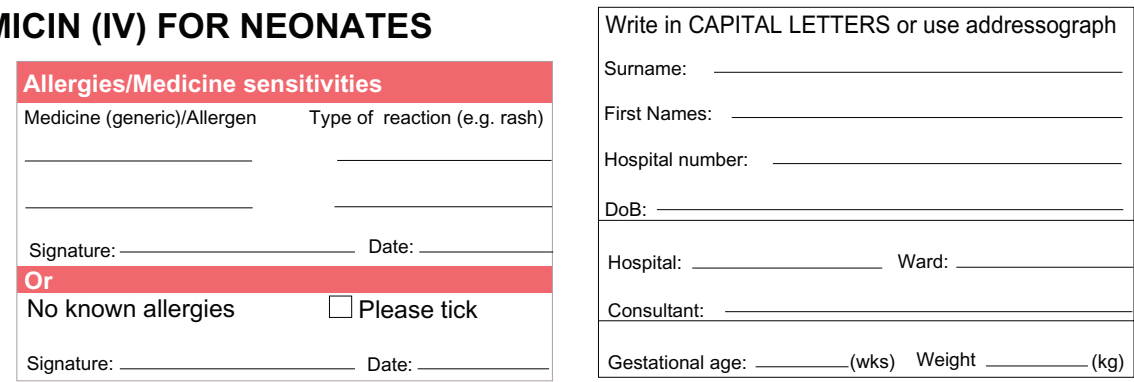

\begin{tabular}{|c|c|c|c|c|c|c|c|c|c|c|c|c|}
\hline \multicolumn{6}{|c|}{ PRESCRIPTION } & \multicolumn{2}{|c|}{ ADMINISTRATION } & \multicolumn{5}{|c|}{ MONITORING } \\
\hline Dose & Date & $\begin{array}{l}\text { Day of } \\
\text { week }\end{array}$ & $\begin{array}{l}\text { GENTAMICIN } \\
\text { dose }(\mathrm{mg})\end{array}$ & $\begin{array}{c}\text { Time } \\
24 \mathrm{hr} \text { clock }\end{array}$ & Signature & $\begin{array}{c}\text { Time } \\
\text { 24hr clock }\end{array}$ & Signature & Sample & $\begin{array}{l}\text { Time of } \\
\text { sample }\end{array}$ & $\begin{array}{l}\text { Result of } \\
\text { sample }\end{array}$ & Action & \multirow{11}{*}{ 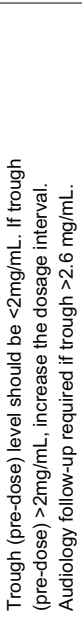 } \\
\hline 1 & & & & & & & & & & & & \\
\hline 2 & & & & & & & & & & & & \\
\hline 3 & & & & & & & & Pre-dose & & & & \\
\hline 4 & & & & & & & & & & & & \\
\hline 5 & & & & & & & & & & & & \\
\hline 6 & & & & & & & & & & & & \\
\hline 7 & & & & & & & & & & & & \\
\hline 8 & & & & & & & & & & & & \\
\hline 9 & & & & & & & & & & & & \\
\hline 10 & & & & & & & & & & & & \\
\hline
\end{tabular}

Figure I Prescription, administration, and monitoring chart for gentamicin. 
provided to record the time it was taken as well as the result. Instructions are also provided prompting the action to be taken depending on the gentamicin trough level.

\section{Design}

For the present study, a retrospective audit was carried out looking at all the reported incidents involving gentamicin over a 7-year period between 2002 and 2008. The data collection was performed by one reviewer who manually examined all submitted clinical incidence forms between the above dates and selected the forms involving gentamicin. The number and type of incident was recorded from the incident form.

\section{Results}

All submitted clinical incident forms between 2002 and 2008 were examined. Over that 7-year period there were a total of 31 clinical incidents involving gentamicin, an average of 4.4 incidents per year. The specific type of each clinical incident was also recorded and can be reviewed in Table 1. This gives a clear breakdown of the number of each type of clinical incident reported in each year under review. Table 2 displays the average number of each type of clinical incident reported both pre- and post-introduction of the gentamicinspecific chart in 2005. It also shows the percentage change in the average number of clinical incidents both pre- and post-introduction of the gentamicin-specific chart.

Since the introduction of the new gentamicin chart in 2005 , there has been a $16 \%(0.75)$ reduction in the average number of clinical incidents involving gentamicin from 4.75 to 4.00 per year.

\section{Discussion}

Despite this reduction in the average annual number of clinical incidents involving gentamicin by $16 \%$ since the gentamicin-specific chart was introduced, given that the aim is to have no clinical incidents involving gentamicin, the total number of clinical incidents is still unacceptably high.

Small sample numbers mean that none of the results were considered to be statistically significant, but when the type of clinical incident involving gentamicin is reviewed in more detail it can be seen that there are some areas where there has been a good improvement. For instance, there have been no further incidents recorded where there wrong dose of gentamicin was given or where a dose was given despite a high level. There has also been a notable improvement $(67 \%)$ in the reduction of average annual incidents where a gentamicin level was not obtained when required.

However in the three years since the introduction of the gentamicin chart there are some areas where there has not been an improvement in the number of reported incidents. In one incident, the standard medicine chart was incorrectly labeled and in another the lab did not phone a high gentamicin level through. Although both these incidents need addressing with further education of staff, we speculate that the introduction of the gentamicin chart is unlikely to have contributed to the incidents, as both of these events would have been as likely to have happened if the standard chart was used.

One area where the new chart may have contributed to increased clinical incidents is where a dose of gentamicin is prescribed correctly, but not administered as it was located on a separate chart and overlooked. Incidents of this type had been anticipated with the introduction of the new chart and the preventative measure recommended was to record on the patient's main chart that the patient was on gentamicin. These incidents could be reduced by stressing the importance of this measure to the potential prescribers.

On reviewing the data, some improvements in the frequency of reported errors was seen following the introduction of the chart. However, while there was some improvement with use of the chart, there were still occasions where a prescribed dose of gentamicin was administered too early, in

Table I Type of clinical incident

\begin{tabular}{|c|c|c|c|c|c|c|c|}
\hline & \multicolumn{4}{|c|}{ Pre-chart } & \multicolumn{3}{|c|}{ Post-chart } \\
\hline & 2002 & 2003 & 2004 & 2005 & 2006 & 2007 & 2008 \\
\hline Dose given too early ( $>$ I hour) & 1 & 1 & 5 & 3 & 2 & 5 & 0 \\
\hline Dose omitted & 0 & 0 & 0 & 0 & 1 & 0 & 1 \\
\hline Wrong dose & 0 & 2 & 0 & 1 & 0 & 0 & 0 \\
\hline No level done & 0 & 2 & 1 & 1 & I & 0 & 0 \\
\hline High level not phoned by lab & 0 & I & 0 & 0 & I & 0 & 0 \\
\hline Dose given despite high level & 0 & I & 0 & 0 & 0 & 0 & 0 \\
\hline Chart not labeled correctly & 0 & 0 & 0 & 0 & 0 & 0 & 1 \\
\hline Total annual number of incidents & I & 7 & 6 & 5 & 5 & 5 & 2 \\
\hline
\end{tabular}


Table 2 Change in clinical incidents with introduction of chart

\begin{tabular}{llll}
\hline & $\begin{array}{l}\text { Average yearly } \\
\text { incidents pre-chart }\end{array}$ & $\begin{array}{l}\text { Average yearly } \\
\text { incidents post-chart }\end{array}$ & $\%$ Change \\
\hline Dose given too early & 2.5 & 2.33 & $-7 \%$ \\
Dose omitted & 0 & 0.67 & $+100 \%$ \\
Wrong dose & 0.75 & 0 & $-100 \%$ \\
No level done & 1 & 0.33 & $-67 \%$ \\
High level not phoned by lab & 0.25 & 0.33 & $+32 \%$ \\
Dose given despite high level & 0.25 & 0 & $-100 \%$ \\
Chart not labeled correctly & 0 & 0.33 & $+100 \%$ \\
Total number of incidents & 4.75 & 4 & $-16 \%$ \\
\hline
\end{tabular}

advance of the prescribed time. The main reason identified was that the antibiotic policy requires gentamicin be given in combination with twice-daily benzylpenicillin and gentamicin was inadvertently administered twice-daily as well. A further modification was made to the chart to require the day of the week to be written to further prompt the correct day of administration. There have been early signs of improvement with no further incidents of this type being recorded since this change. Further data collection in subsequent years will be required to see if this trend is sustained.

Although the above results appear to show clear trends, they must be interpreted with caution. The number of available incident forms over the 6 -year period was small. The audit also relies on the assumption that reported incident forms accurately reflect errors involving gentamicin. This assumption, combined with the small number of forms, means that the non-reporting of a single incident can have a significant impact on the apparent trends in gentamicin error.

Another factor that may affect the results is that, as time has progressed, the reporting of clinical incidents has become a much more routine part of neonatal staff working practice. This rising interest in clinical governance may mean that there has been an increased rate of incident reporting relating to staff awareness of its importance. However, this factor does not seem to have influenced this audit as our results show fewer incidents with increasing time. It may, however, help explain why the improvement was not as great as expected in some areas and why there was such an increase in reported incidents between 2002 and 2003.

The above results highlight how the introduction of a chart for prescribing, administration, and monitoring of gentamicin has reduced reported errors in use of this high risk medicine. There is still room for improvement, however. It is essential that training and education in the prescription of gentamicin and use of its associated chart is provided at induction programs. In addition, an annual update on gentamicin prescribing, use of the chart, and audit results will be delivered for existing staff. Other neonatal units in the province are now using this chart, which will assist junior doctors as they rotate between different units. Following the modification made to the chart in 2007 to include a day of the week column, no further revisions have been identified as required for the chart. The need for continued reporting of incidents in the use of gentamicin should be encouraged with periodic review of reported incidents to identify further areas for improvement. There is a plan to re-audit this matter on a yearly basis. If there is still no significant decrease in the number of gentamicin-related incidents, electronic prescribing will be considered as a way forward, as this has been shown to reduce medication errors. ${ }^{5}$

\section{Conclusion}

There has been some reduction in the number of gentamicin-related clinical incidents with the introduction of a gentamicin-specific chart, however errors are still occurring. Recommendations include the introduction of regular training on gentamicin prescription for new staff and a mandatory yearly update for permanent staff. There is a plan to re-audit this topic yearly, with consideration of electronic prescribing in the future to further diminish errors.

\section{Disclosures}

The authors report no conflicts of interest in this work.

\section{References}

1. Runciman WB, Roughead EE, Semple SJ, Adams RJ. Adverse drug events and medication errors in Australia. Int $J$ Qual Health Care. 2003;15(Suppl 1):i49-i59.

2. Ghaleb MA, Barber N, Franklin BD, Yeung VWS, Khaki ZF, Wong ICK. Systematic review of medication errors in pediatric patients. Ann Pharmacother. 2006;40:1766-1776. 
3. Safety in doses: medication safety incidents in the NHS. The fourth report from the patient safety observatory, National Patient Safety Agency, 2007.

4. Paediatric Formulary Committee. BNF for Children 2008. London: BMJ Publishing Group. RPS Publishing and RCPCH Publications; 2008.
5. Conroy S, Carroll WD. Prescribing in paediatrics. Arch Dis Child. 2009;94:55-59.
Clinical Audit

\section{Publish your work in this journal}

Clinical Audit is an international, peer-reviewed, open access journal focusing on the processes and outcomes of clinical audit in any area of healthcare. All aspects of patient care are addressed within the journal and practitioners from all disciplines are invited to submit their work. Areas covered include: Publication of audits; How an audit has changed practice;

Submit your manuscript here: http://www.dovepress.com/clinical-audit-journal

\section{Dovepress}

Practical tips on how to do audits and to avoid pitfalls; How audits have changed patient care; Calls and justifications for new audits. The manuscript management system is completely online and includes a very quick and fair peer-review system, which is all easy to use. Visit http://www.dovepress. com/testimonials.php to read real quotes from published authors. 